\title{
Single and Combined Effects of Antibacterial Activities of Fruit and Stem Bark Extracts of Tetrapleura Tetraptera on Streptococcus Mutans and Pseudomonas Aeruginosa
}

\author{
Gberikon G.M1 , Agbulu C.01, Adeoti I.I.1
}

${ }^{1}$ University of Agriculture Makurdi, Benue state

\begin{abstract}
Single and combined effect of the antibacterial activities of fruit and stembark extracts of Tetrapleura tetraptera was carried out against Streptococcus mutans and Pseudomonas aeruginosa. Samples of T.tetraptera fruits were purchased in Wukari market, Taraba State. Stem bark samples were collected from Vandeikya, Benue State of Nigeria. Phytochemical analyses were carried out on both samples in the laboratory, Department of Biological Sciences, University of Agriculture, Makurdi. Phytochemical screening showed the presence of flavonoids, saponins, tannins, steroids, alkaloids, phlobatannins, anthraquinones, glycosides and reducing sugars in varying concentrations in fruit and stem bark samples. Antibacterial activity of extracts of fruit and stembark of Tetrapleura tetraptera singly and combined was studied against Pseudomonas aeruginosa and Streptococcus mutans. Results showed that extract of fruit of test plant gave an inhibition zone of $21.00 \mathrm{~mm}$ against Pseudomonas aeruginosa, $08.33 \mathrm{~mm}$ against $S$. mutans . Extract of stem bark gave $12.00 \mathrm{~mm}$ against $S$. mutans and no antibacterial activity against Pseudomonas aeruginosa. Combined extracts of Tetrapleura tetraptera fruit and stembark showed antibacterial activity on Pseudomonas aeruginosa giving an inhibition zone of $16.67 \mathrm{~mm}$ and $S$. mutans an inhibition zone of $10.33 \mathrm{~mm}$. There was significant difference $(\mathrm{p}<0.025)$ between the antibacterial effects of extracts of fruit and stem bark of Tetrapleura tetraptera singly and combined as shown in this study. Minimum inhibitory concentration of test organisms subjected to single and combined extracts of fruit and stem bark was $100 \mathrm{mg} / \mathrm{ml}$ except for P.aeruginosa which showed that concentrations $(\mathrm{mg} / \mathrm{ml})$ of stem bark extract used singly was not enough to inhibit its growth, except the combined extract which inhibited its growth at $100 \mathrm{mg} / \mathrm{ml}$.
\end{abstract}

Keywords: Pseudomonas aeruginosa, Streptococcus mutans Tetrapleura tetraptera, Phytochemicals flavonoids, saponins, tannins, steroids, alkaloids, phlobatannins, anthraquinones, glycosides, reducing sugar, antibacterial, ethanolic, combined, single

\section{Introduction}

The use of plants as medicines predates written human history. Many of the pharmaceuticals currently available to physicians have a long history of use as herbal remedies (Lichterman, 2004). The use of plants with medicinal values in treating human diseases is almost universal. Medicines from plant sources is more affordable than expensive modern drugs (Lai and Roy, 2004). Global estimates indicate that $80 \%$ of about 4 billion population cannot afford drugs from Western pharmaceutical industry and have to rely on medicinal plants which are mainly derived from plant materials (Joy et al., 1998). In many of the developing countries, the use of plant drugs is increasing because modern life saving drugs are beyond the reach of three quarters of the third world's population (Joy et al., 1998).

In tropical and subtropical countries, microorganisms cause serious infections to both human and animal. Antibiotic resistance by this organisms has become a worldwide apprehension (Masud et al.,2014). Many researchers have reported that the effectiveness of natural plants against microorganisms cannot be over emphasized (Masud et al.,2014).

Against the above background, this study was undertaken to evaluate the susceptibility of

This article is published under the terms of the Creative Commons Attribution License 4.0

Author(s) retain the copyright of this article. Publication rights with Alkhaer Publications.

Published at: http://www.ijsciences.com/pub/issue/2015-04/

Article Number: V4201504693; Online ISSN: 2305-3925; Print ISSN: 2410-4477 
Pseudomonas aeruginosa and Streptococcus mutans to extracts of fruit and stembark of T.tetraptera singly and combined for treatment of infections caused by these organisms.

\section{MATERIALS AND METHODS}

\section{Collection of plant materials}

Stem bark of the test plant (Tetrapleura tetraptera) for this study was collected in Vandeikya local government area of Benue State. Fruit samples were bought from railway market at Makurdi and from new market, Wukari local government area in Taraba state. The plant parts were package in sterile polythene bags and transported to the laboratory, Department of Biological Sciences, University of Agriculture, Makurdi for identification and analyses.

Preparation of plant materials: The collected plant parts were shade dried at $27{ }^{\circ} \mathrm{C}$ for a period of one week and crushed into small pieces using a clean mortar and pestle, crushing was done separately. They were later taken to the laboratory, Department Biological Sciences, University of Agriculture, Makurdi for extraction process.

Preparation of plant for extraction using ethanol as solvent: The extract of the plant materials were obtained using the cold maceration method described by Umeh et al, 2005. Fifty gram $(50 \mathrm{~g})$ of powdered plant materials (fruit and stembark) was weighed into clean sterile bottles. Each weighed-out plant parts was extracted using $250 \mathrm{ml}$ ethanol separately in tightly covered bottles and left for 48hours at room temperature. The resultant suspensions were filtered into sterile beakers, and filtrates collected was refiltered using Whatmans No. 1 filter paper into sterile sample bottles. They were labelled appropriately and stored in plastic bags at $-20{ }^{\circ} \mathrm{C}$ for further analyses.

\section{Phytochemical screening}

Plant materials extracted using ethanol solution were subjected to phytochemical screening according to the method described by Odebiyi and Sofowora (1978); Okerulu and Ani (2001) to ascertain the presence or absence of some specific active metabolites such as tannins, saponins, flavonoids, reducing sugars, alkaloids, steroids, anthraquinones, glycosides and phlobatannins

\section{Identification and confirmatory test on test organisms}

Test organisms used for this study were Streptococcus mutans and Pseudomonas aeruginosa the stock isolates of these organisms were obtained from Tosema specialist diagnostic laboratory, Makurdi. A well isolated colony of the bacteria was picked using sterile inoculating wire-loop and transferred into nutrient agar and blood agar slant, and incubated at $37^{\circ} \mathrm{C}$ for 24 hours before susceptibility test. The agar slants were stored at $4^{\circ} \mathrm{C}$. Identification and confirmatory test were carried out on the organisms using appropriate biochemical tests like catalase, coagulase Pyrrolidonyl arylamidase (PYR) test, oxidase, bile solubility test, Optochin susceptibility test and Glucose fermenting test.

\section{Determination of antibacterial activity}

The disc diffusion method was used (Salie et al., 1996; Nostro et al., 2000). Stock solutions used contain $200 \mathrm{mg} / \mathrm{ml}$ of each extract for both fruit and stem bark. Blood agar plates were inoculated with the organisms, within $15 \mathrm{~min}$ of inoculation of the plates, the drug/extract-impregnated disc was placed on the agar surface, with at least $24 \mathrm{~mm}$ (centre to centre) (Jorgensen and Turnidge, 2003). The disc was placed with a sterile forceps and then gently pressed down onto the agar surface to provide uniform contact. The plates were allowed to stand for few minutes to enable the extracts diffuse into the agar. Standard ofloxacin antibiotic discs (10microgram/disc) was used as control and was similarly applied on plates seeded with the organism. Sterile disc loaded with $0.1 \mathrm{ml}$ of sterile distilled water was used as negative control. Within 15 minutes of applying the disc, the plates were inverted and incubated at $37^{\circ} \mathrm{C}$ for $24 \mathrm{hrs}$ (Salie et al., 1996). All tests were performed in triplicate and the antibacterial activity was expressed as the mean diameter of inhibition zones $(\mathrm{mm})$ produced by the plant extracts. The diameters of the zones of inhibition produced around the disc was measured with a transparent ruler to the nearest millimetre (Salie et al., 1996). The measurements taken were recorded. Extracts of the fruit, and stembark that inhibited bacterial growth were subjected to further (quantitative) tests to determine their minimum inhibitory concentrations (MICs).

\section{Determination of minimum inhibitory concentration (MIC)}

After phytochemical screening, the extract that showed potent antibacterial activity was further tested to determine the minimum inhibitory concentration (MIC) of the bacterial samples. The MICs of these extracts was determined by broth micro dilution method.

\section{Dilution of extracts}

The stock solution was serially diluted with the extraction solvent (ethanol), in sterile test tubes labelled and arranged from the highest to lowest concentration of extracts desired (400mg, 200mg,150mg, 100mg,50mg and 25mg). Using a sterile pipette (or $2 \mathrm{ml}$ needle and syringe), $1 \mathrm{ml}$ of solvent was added to each of the 6 tubes, except the first and second tubes. $2 \mathrm{ml}$ of extract was added to the 
first tube $(400 \mathrm{mg}), 1 \mathrm{ml}$ of the extract $(200 \mathrm{mg} / \mathrm{ml})$ was added to the second and third tubes, and the contents of the third tube agitated on a Vortex mixer. $1 \mathrm{ml}$ of the solution in the third tube was transferred to the fourth tube, and the process continued through the next to the last tube from which $1 \mathrm{ml}$ was removed and discarded. $0.25 \mathrm{ml}$ of extract was later added to the third tube to make the concentration $150 \mathrm{mg}$. No extract was added to the $7^{\text {th }}$ tube which served as a negative growth control, 10microgram of ofloxacin was used as positive control (that prevented bacterial growth). An equal volume of a fixed bacterial culture was added to the tubes and incubated at $37{ }^{\circ} \mathrm{C}$ for 24 hrs. After which tubes were examined for turbidity. The lowest concentration that shows no visible growth (turbidity) was noted and recorded as the MIC values (Salie et al., 1996).

Statistical analysis: Statistical package for the social sciences (SPSS) version 20 was used to analyse the data obtained

\section{RESULTS AND DISCUSSION}

TABLE 1: Phytochemical screening of Tetrapleura tetraptera stembark and fruit extracts

\begin{tabular}{lcc}
\multicolumn{1}{c}{ Phytochemicals } & Stembark & Fruit \\
\hline Saponins & ++ & + \\
Tannins & ++ & + \\
Reducing sugar & + & - \\
Phlobatannins & + & + \\
Anthraquinones & + & + \\
Steroids & + & + \\
Flavonoids & + & + \\
Glycosides & - & + \\
Alkaloids & + & +
\end{tabular}

Key: $+=$ present, $-=$ absent

TABLE 2: Antibacterial activity of single and combined fruit and stembark extract of Tetrapleura tetraptera on P.aeruginosa and S.mutans

\begin{tabular}{|c|c|c|c|c|c|c|}
\hline Extracts & $\begin{array}{r}\text { fruit extra } \\
\text { P.aeruginosa }\end{array}$ & S.mutans & $\begin{array}{r}\text { stembark ext } \\
\text { P.aeruginosa }\end{array}$ & tract & $\begin{array}{l}\text { fruit \&stemb } \\
\text { P.aeruginosa }\end{array}$ & $\begin{array}{l}\text { ark extract combined } \\
\text { S. mutans }\end{array}$ \\
\hline Ethanol & 21.00 & 08.33 & 0.00 & 12.00 & 16.67 & 10.33 \\
\hline $\mathrm{D} /$ water & 0.00 & 0.00 & 0.00 & 0.00 & 0.00 & 0.00 \\
\hline Ofloxacin & 31.00 & 11.67 & 26.00 & 23.00 & 12.00 & 0.00 \\
\hline
\end{tabular}

T-cal $=2.857, \mathrm{p}<0.025, \mathrm{t}-\mathrm{tab}=2.776(\mathrm{n}-1=4)$

Mean diameter of zone of inhibition are expressed in millimeter.

Key:D/water-distill water

TABLE 3: Minimum inhibitory concentration (MIC) of single and combined fruit and stembark extracts of Tetrapleura tetraptera.

\begin{tabular}{|c|c|c|c|c|c|c|c|}
\hline Plant & test & & conc & ntrati & in $m$ & $\mathrm{ml}$ & \\
\hline Extract & organisms & 400 & 200 & 150 & 100 & 50 & 25 \\
\hline Stem bark & S. mutans & - & - & - & $*$ & + & + \\
\hline Fruit & S. mutans & - & - & - & $*$ & + & + \\
\hline Stembark & P. aeruginosa & + & + & + & + & + & + \\
\hline Fruit & P. aeruginosa & - & - & - & $*$ & + & + \\
\hline Combined & S. mutans & - & - & - & $*$ & + & + \\
\hline Combined & P. aeruginosa & - & - & & $*$ & + & + \\
\hline
\end{tabular}

Key: $+=$ indicate growth, $-=$ indicate no growth and * = indicate MIC 


\section{Discussion}

Antibacterial activity of Tetrapleura tetraptera plant has been established in this study. Uchechi and Chigozie (2010) opined that Tetrapleura tetraptera plant has some antibacterial properties. Fruits of Tetrapleura tetraptera extracted with ethanol exhibited antibacterial activity against P.aeruginosa and $S$. mutans showing maximum zone of inhibition of $21.00 \mathrm{~mm}$ against Pseudomonas aeruginosa and 08.33 against S.mutans. Susceptibility of both organisms to fruit extract could be that, concentrations of phytochemicals in fruit extract is in the required quantity to cause inhibition of the test organisms. Stembark extract showed no antibacterial activity against P.aeruginosa, but gave an inhibition zone of $12.00 \mathrm{~mm}$ against $S$. mutans. The susceptibility of $S$. mutans to stembark extract could be as a result of varying concentrations of phytochemical components in the fruit and stembark of the plant. Combined extracts of fruit and stem bark in the same ratio also showed inhibition against P.aeruginosa and $S$. mutans. Highest zone of inhibition was observed against Pseudomonas aeruginosa $(16.67 \mathrm{~mm})$. Least zones of inhibition was observed against Streptococcus mutans $(10.33 \mathrm{~mm})$. Combined effect of fruit and stem bark extract was able to exert antibacterial activity against P.aeruginosa as opposed to stembark extract. This is because the bioactive substance that was lacking in the stembark to exert antibacterial activity against P.aeruginosa was found in the fruit after combining fruit and stembark extracts. Phytochemical analyses, revealed that saponins, tannins, steroids, phlobatannins, alkaloids, anthraquinones, and flavonoids were more in one extract than the other.These groups of compounds form the active principles that confer antibacterial activity on the plant. Minimum inhibitory concentration for test organisms subjected to single and combined extracts of fruit and stem bark was $100 \mathrm{mg} / \mathrm{ml}$ except for P.aeruginosa which shows that concentrations $(\mathrm{mg} / \mathrm{ml})$ of stem bark extract used singly was not enough to inhibit its growth, except the combined extract which inhibited its growth at $100 \mathrm{mg} / \mathrm{ml}$. this could be attributed to the synergistic effect of the combined extract on P.aeruginosa.

\section{Conclusion}

It was therefore concluded based on the results of this study that extract of the test plant, Tetrapleura tetraptera possess antibacterial activity when they are used singly and combined. Extracts of Tetrapleura tetraptera stem bark could not exert antibacterial activity on P.aeruginosa, but combined extracts of fruit and stem bark was able to inhibit growth of P.aeruginosa as a result of the synergistic effect. Combined extracts of fruit and stem bark of the test plant should be used in treating infections caused by these organisms.

\section{References}

I. Jorgensen, J. H., and J. D. Turnidge. (2003). Susceptibility test methods: Dilution and Disc diffusion methods. Manual of Clinical Microbiology. $8^{\text {th }}$ ed. $1108-112755(3) 205-238,243-251$.

II. Joy, P.P., Thomas, J., Mathew, S.S., and Karia, B.P.(1998). Medicinal Plants. Aromatic and Medicinal Research Station, Kerula India. Pp 1-3.

III. Lai, P.K and Roy, J. (2004). Antimicrobial and chemo preventive properties of herbs and spices. Curr Med. Chem. 11(11):1451-1460 http://dx.doi.org/10.2174/0929867043365107

IV. Lichterman, B.L.(2004). "Aspirin: The Story of a Wonder Drug". British Medical Journal. 329(7479): 1408 .

http://dx.doi.org/10.1136/bmj.329.7479.1408

V. Masud, S.M., Rana, M.P., Billah, M. Raju, G.S. (2014). Susceptibility of Microorganisms to selected Medicinal Plants in Banglandesh. Asian Pacific Journal of Tropical $\begin{array}{lll}\text { Biomedicine. } & 4(11) & 911-917\end{array}$ http://dx.doi.org/10.12980/apjtb.4.201414b362

VI. Nostro, A., Germanŏ, M.P., D’Angelo, V., Marino, A. and Cannattelli, M.A. (2000): Extraction Methods and Bioautography for Evaluation of Medicinal plants for Antimicrobial activity. Lett. Appl. Microbiol ., 30:379$384 . \quad$ http://dx.doi.org/10.1046/j.1472 765x.2000.00731.x

VII. Odebiyi, O. O. and Sofowora, E. A. (1978). Phytochemical screening of Nigeria medicinal plants II Lloydia 41: 2234-246.

VIII. Okerulu, I. O. and Ani, C. J. (2001). The phytochemical analysis and antibacterial screening of extracts of Terracarpidium conophorum. Journal of Chemical Society of Nigeria 26(1): 53-56.

IX. Salie, F.; Eagles, P. F. K. and Lens, H. M. J. (1996). Preliminary antimicrobial screening of four South African Asteraceae species. J. Ethnopharmacol., 52(1):27-33. http://dx.doi.org/10.1016/03788741(96)01381-5

X. Uchechi, N. E. and Chigozie, F. O. (2010). Antibacterial activity of Tetrapleura tetraptera Taub. Pod extracts. International Journal of Pharma and Bio Sciences.p 734. Vol.1.

XI. Umeh, E. U., Oluma, H. O. A. and Igoli, J. O. (2005). Antibacterial screening of four local plants using an indicator- based microdilution technique. Afr. J. Trad. 2(3): 238-243. 